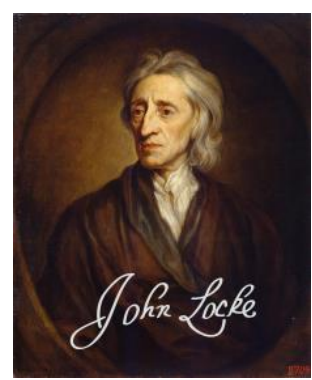

LOCKE STUDIES

Vol. 14

https://doi.org/10.5206/ls.2014.726 | ISSN: 1476-0290

Originally published: 2014

Published online: 19 FEBRUARY 2018

(C) Locke Studies, 2014

\title{
Certainty and Sensitive Knowledge
}

\section{DAVID SOLES (WICHITA STATE UNIVERSITY)}

Recommended citation:

Soles, David. "Certainty and Sensitive Knowledge." Locke Studies 14 (2014): 159-176.

https://doi.org/10.5206/ls.2014.726

For more information about this article:

https://ojs.lib.uwo.ca/index.php/locke/article/view/726

Locke Studies is published by The John Locke Society.

This is an open access article published under the terms of the Creative Commons Attribution-

NonCommercial-ShareAlike 4.0 International license, which permits use, distribution and reproduction in any medium, provided the original work is properly cited and shared under the original license. 


\title{
CERTAINTY AND SENSITIVE KNOWLEDGE
}

\author{
DAVID SOLES
}

In 'Is Locke's Theory of Knowledge Inconsistent?' and 'Locke's 'Sensitive Knowledge': Knowledge or Assurance' 2 Samuel Rickless has reopened the issue of whether Locke believes that what he calls sensitive knowledge really counts as knowledge. Rickless maintains that, having argued that knowledge requires certainty and having admitted that our awareness of objects external to the mind falls short of the certainty of intuition and demonstration, Locke is forced to concede that beliefs about the existence of objects external to the mind do not satisfy his criterion of knowledge; while some such beliefs reach such a high level of probability that we may be assured of them and they may be allowed to 'pass under' the name of knowledge, such beliefs are not really knowledge. In this case, calling such beliefs sensitive knowledge is to use 'knowledge' as an honorific; even though they fall short of the criterion of knowledge, for all practical purposes, we will let them pass as knowledge. Rickless adduces three considerations in support of this interpretation: first, certainty does not admit of degrees so, in conceding that beliefs about the existence of extra-mental objects fall short of the certainty of intuition and demonstration, Locke is conceding that such beliefs literally do not constitute knowledge; second, Locke tends to speak of our assurance of the existence of extra-mental objects and 'assurance' is a technical term indicating an epistemic level

${ }^{1}$ Samuel Rickless, 'Is Locke's Theory of Knowledge Inconsistent?', Philosophy and Phenomenological Research 77, (2008): 83-104.

2 Samuel Rickless, 'Locke's 'Sensitive Knowledge': Knowledge or Assurance?', in Oxford Studies in Early Modern Philosophy, vol. 7 (Oxford, forthcoming). A pre-publication copy of this paper was accessed through Professor Rickless's link on the University of California, San Diego Philosophy Department web page: http://philosophyfaculty.ucsd.edu/faculty/rickless/Rickless/Research_files/LockeSK-FIn al.pdf 
somewhat less than certainty; third, to say that something 'passes under' the name of a sort is to indicate that it is not really of that sort but that the name of the sort will be applied to it for practical purposes.

Nathan Rockwood, in 'Is Sensitive Knowledge Knowledge?', considers each thesis and through careful textual analysis rebuts them. ${ }^{4}$ First, Locke does explicitly and repeatedly assert that there are degrees of certainty and knowledge; consequently, one cannot argue, as Rickless does, that because certainty does not admit of degrees that Locke believes that our awareness of the existence of extra-mental objects, which falls short of the certainty of intuition and demonstration, is not genuine knowledge. Second, in places Locke uses 'certainty' and 'assurance' as synonyms; consequently, there are no grounds for supposing that he is employing 'assurance' in a technical sense to indicate an epistemic status lower than knowledge, i.e. there are no grounds for supposing that Locke believes that assurance falls below the lowest degree of certainty and knowledge. Third, Locke occasionally uses the expression 'passes under' where it is clear that he believes that the object which passes under the name of a class is a full-fledged member of the class; consequently, we cannot conclude that in saying that beliefs about the existence of extra-mental objects pass under the name of knowledge Locke is indicating that such beliefs do not count as knowledge in the full-fledged sense of the word.

Although Rockwood's arguments, based on overwhelming textual evidence, are persuasive in rebutting Rickless's interpretation, there is much more that could be said. Is Locke simply confused or worse in maintaining that there are degrees of certainty and that some beliefs about the existence of extra-mental objects attain a sufficient degree of certainty to be classed as

3 Nathan Rockwood, 'Is Sensitive Knowledge Knowledge?', Locke Studies 13, (2013): 15-31.

4 Given the accessibility of Rockwood's paper, for the sake of brevity I will not rehearse those passages here. Also, they will be familiar to anyone with a nodding acquaintance with the Essay. 
knowledge? The objective of this paper is to clarify Locke's use of 'certainty' and his grounds for maintaining that some beliefs about the existence of extra-mental objects reach a degree of certainty that constitutes knowledge. Hopefully, getting clear on these issues will put to rest the perennial suggestion that there is some sort of unresolvable tension between the equation of knowledge and certainty and the assertion that we can have knowledge of the existence of extra-mental objects. It helps here if, instead of reading Locke as a precursor to Berkeley, Hume and other phenomenalists, we treat him as a successor to Bacon, Descartes and Hobbes.

The first thing to emphasize is that philosophers of the seventeenth century are working within a tradition that cheerfully countenances talk of degrees of certainty. Even stronger, it would not even occur to most of them to question whether there are levels or degrees of certainty. Bacon, for instance, in the preface to the New Organon, states that he proposes 'to establish progressive stages of certainty" ${ }^{5}$ and in aphorisms XVII and CXVI of Book One of that work he claims that the results of his method are 'more certain' than those of others. In discussing Bacon's use of 'certainty' and arguing that Bacon both allows for degrees of certainty and is willing to class as certain some beliefs which fall short of theoretical infallibility, Peter Urbach quotes Glanville's distinction between two levels of certainty. According to Glanville, certainty

is taken either (1.) for a firm assent to anything, of which there is no reason to doubt; and this may be called Indubitable Certainty; or (2.) for an absolute Assurance, that things are as we conceive and affirm, and not possible to be otherwise, and this is Infallible Certainty. ${ }^{6}$

5 Francis Bacon, The New Organon, ed. Fulton Anderson (London, 1960), 33.

6 J. Glanville, Essays on Several Important Subjects in Philosophy and Religion (London, 1676), 47. Quoted in Peter Urbach, Francis Bacon's Philosophy of Science (New York, 1987), 45. 
As Urbach emphasizes, Glanville believes both that infallible certainty is impossible to achieve and that indubitable certainty is all that Bacon and his (Glanville's) contemporaries in the Royal Society are hoping to achieve. Citing thinkers as diverse as William Faulk, William Gilbert, and William Harvey, in addition to Glanville, Urbach makes a convincing case for the thesis that Bacon and the virtuosi of the Royal Society tend to use 'certainty' as a synonym for 'firm assent where there is no reason to doubt' and that such assent can be more or less firm, leading to talk of levels or degrees of certainty.

It is not, however, merely philosophers with empiricist proclivities who are inclined to talk of degrees of certainty. Descartes, for instance, draws an important distinction between moral certainty and metaphysical or absolute certainty where moral certainty is 'sufficient certainty for application to ordinary life, even though [what is believed] may be uncertain in relation to the absolute power of God...Absolute certainty [however] arises when we believe it is wholly impossible that something should be otherwise than we judge it to be'. ${ }^{7}$ The French version of this passage, translated by John Cottingham, maintains that 'moral certainty is certainty which is sufficient to regulate our behaviour, or which measures up to the certainty we have on matters relating to the conduct of life which we never normally doubt, though we know that it is possible, absolutely speaking, that they may be false'. ${ }^{8}$ Descartes insists that, while someone who has not clearly and distinctly perceived that God exists and is not a deceiver cannot be absolutely or metaphysically certain that two plus three equals five, that she possesses a body, that other people exist, or that there is a city in Italy called Rome, she can be morally certain

7 Rene Descartes, Principles of Philosophy, Part Four, Articles 206 \& 207, in The Philosophical Writings of Descartes, trans. J. Cottingham, R. Stoothoff and D. Murdoch, (3 vols., Cambridge, 1984-91), i, 289-90.

8 Ibid., 289. 
of these things. ${ }^{9}$

In the absence of any explicit statement to the contrary and given his talk of degrees of certainty, his admiration for Bacon, his close association with other members of the Royal Society and his careful study of Descartes, it is only reasonable to suppose that Locke employs a concept of certainty that countenances talk of degrees, levels or types of certainty. To even suppose otherwise is the height of anachronism. Furthermore, like Glanville and his contemporaries in The Royal Society, for Locke to say that something is certain may mean no more than that there are no reasonable grounds for doubt and that it is held with firm assent. And also with his predecessors and contemporaries, he believes

9

An anonymous referee for this journal has raised the interesting question of whether Descartes would classify moral certainty as knowledge. While there are passages which seem to suggest that he sometimes does, this is not a question that needs to be definitively answered here. Beginning with the first point, Descartes illustrates the notion of moral certainty with the following example:

Suppose for example that someone wants to read a letter written in Latin but encoded so that the letters of the alphabet do not have their proper value, and he guesses that the letter B should be read whenever the letter A appears, and $C$ when $B$ appears, i.e. that each letter should be replaced by the one immediately following it. If, by using this key, he can make up Latin words from the letters, he will be in no doubt that the true meaning of the letter is contained in these words. It is true that his knowledge is based merely on conjecture, and it is conceivable that the writer did not replace the original letters with their immediate successors in the alphabet, but with others, thus encoding quite a different message; but this possibility is so unlikely <especially if the message contains many words $>$ that it does not seem credible. (Ibid., p. 209, my emphasis)

Descartes here explicitly refers to the person's moral certainty that the message has been properly decoded as knowledge. Also, as that same referee notes, in the Meditations Descartes maintains that, until he became aware of the true God, he was incapable of perfect knowledge, leaving open the possibility that there might be knowledge which is less than perfect (op. cit., ii, 49). While the suggestion that Descartes might classify moral certainty as knowledge is an intriguing possibility, as suggested above, it is not something which needs to be resolved here. The point of the present discussion is merely that talk of degrees or types of certainty is wide-spread in the seventeenth century and, consequently, one cannot assume that Locke is being confused, incoherent or inconsistent in talking about degrees of certainty. Whether Locke believes that the degree of certainty attained via perceptual experience is sufficient to count as knowledge is an independent question and one that can be addressed independently of the question of whether Descartes considers moral certainty a type of knowledge. For the record, however, to treat moral certainty as a type of knowledge seems to me to be anathema to the whole tenor of Descartes's enterprise. 
that there are several degrees of assent which count as certainty-a point returned to below.

But it might be argued that Locke himself admits that there are considerations which call into question the very existence of extra-mental objects and hence it is not unreasonable or irrational to doubt of their existence. Consequently, even if 'certainty' means something as weak as 'firm assent where there is no reason to doubt', our assurance of the existence of extra-mental objects does not satisfy the criterion. But such an objection assumes that he takes those considerations to be weighty enough to raise reasonable doubts about the existence of an external world. Does he really believe that the sceptics' considerations call into question the very existence of an external world or does he merely mention them to dismiss them as unreasonable?

Here it might be useful to emphasize that like his contemporaries in The Royal Society Locke is never tempted to search for anything analogous to Descartes's absolute or metaphysical certainty, the absolute impossibility of being mistaken. To briefly draw the contrast, at the end of his first meditation it occurs to Descartes that a deceiving God or a malicious demon could cause him to believe with the utmost conviction that two plus three equals five or that a square has only four sides even though these beliefs are false; consequently, he cannot be absolutely or metaphysically certain of them until he has proved that there can be no such deceiving God or malicious demon. He then embarks on what Harry Franfurt famously dubbed 'the validation of reason', ${ }^{10}$ the project of demonstrating that reason, when properly employed, is reliable and capable of attaining truth. But, Locke believes, the project is a dead-end failure; to use our cognitive faculties (and what else could one use?) to demonstrate that our most basic cognitive faculties are reliable is circular. Locke sees no need to argue that our most basic cognitive faculties are reliable: there are no attempts to justify the

10 Harry Frankfurt, 'Descartes' Validation of Reason', American Philosophical Quarterly 2, (1965): 149-56. 
supposition that our most basic cognitive operations such as intuition, deduction or sensation are reliable. Speaking of intuition, the most basic of cognitive operations, he writes (surely thinking of Descartes), "He that demands a greater Certainty than this, demands he knows not what, and shews only that he has a mind to be a Sceptick, without being able to be so' (IV. ii. 1, 531). This thesis that our most basic cognitive operations cannot be called into question is repeatedly emphasized. It is given that the 'Mind ...has a native Faculty to perceive the Coherence, or Incoherence of [any of] its Ideas' (IV. xvii. 4, 671) and, when it comes to our cognitive faculties, '[we] have Reason to be well satisfied with what God hath thought fit [to give us]' (I. i. 5, 45). We have no reason to complain about the narrowness of our cognitive abilities for 'they are very capable' of being employed in their proper domains: 'The Candle, that is set up in us, shines bright enough for all our Purposes' (I. i. 5, 46) and 'no body can, in earnest, be so sceptical as to be uncertain of the Existence of those Things which he sees and feels' (IV. xi. 3, 631).

The thought that a malicious demon might be deceiving him into believing that two plus three equals five when it really does not Locke deems unworthy of serious consideration or refutation. While that sceptical challenge can be coherently stated and it is not clear that it can be non-circularly refuted, it is not capable of generating genuine, as opposed to 'feigned', doubt. With Glanville and others of the Royal Society, he believes that the absolute or metaphysical certainty for which Descartes is searching is unattainable and unnecessary. Glanville's indubitable is all we need or can achieve and to be indubitably (or morally) certain a belief need not be immune from what Descartes variously calls hyperbolic, extravagant or metaphysical doubt. A well founded belief for which there are no reasonable grounds for doubt may be said to be certain. Not searching for the absolute or metaphysical certainty Descartes requires, Locke simply dismisses the

11 John Locke, An Essay concerning Human Understanding, ed. P. H. Nidditch (Oxford, 1975). 
hyperbolic doubts of the first meditation as pretenses of doubt where genuine doubt is impossible. He has a similar attitude to the challenges of external world scepticism. They are hyperbolic and not worth taking seriously.

To begin defending that last claim, when the issue of external world scepticism is introduced at IV. ii. 14 Locke notes that some people (implicitly excluding himself) think that there is a problem here because, even if one is not being affected by an external object, it is possible to have in one's mind an idea which is indistinguishable from the idea one would have were one being affected by a particular external object. As he sees it then, the challenges of external world scepticism turn on the claim that, since the non-veridical mental contents of dreams, hallucinations, etc., are qualitatively indistinguishable from the mental contents of veridical perceptual experience, and since the mental contents of dreams, hallucinations, etc. do not correspond to extra-mental realities, we are not justified in supposing that the contents of what we call veridical perceptual experience correspond to extra-mental realities. Locke, however, emphatically rejects the presupposition of this argument - that there are no qualitative differences between the experiences of smelling a rose or tasting wormwood and dreaming, hallucinating, or imagining that one is smelling a rose or tasting wormwood. It is claimed that there is a 'manifest' difference between these experiences of which one is 'invincibly conscious'. ${ }^{12}$ This is reiterated at IV. xi. 5 where the idiom 'manifest difference' is redeployed and it is further claimed that 'there is no body who doth not perceive the difference', suggesting that the doubts of external world scepticism are not sincere. That suggestion is reinforced by the claim that "no body can, in earnest, be so sceptical as to be uncertain of the existence of those Things, which he sees and feels' (IV. xi. 5, 631). The external world sceptic simply cannot be in earnest; the doubts are feigned or pretenses.

Locke also believes that there is something epistemologically incoherent about attempts to doubt the existence of an extra-mental

12 Essay, IV. ii. 14, 537. 
reality. External world scepticism is summarily dismissed with the remark that we cannot even 'talk of Knowledge it self, but by the help of those Faculties, which are fitted to apprehend even what Knowledge is' (IV. xi. 3, 631). The incoherency hinted at by this cryptic remark is thought to arise on two related, but distinct, levels. First, talk of the non-veridicality of dreams, illusions, hallucinations, etc. can gain a foothold only by contrasting them with veridical perceptual experience, i.e. by assuming that there is a distinction between such experiences and veridical perceptual experiences and that the distinction consists in the fact that the mental contents of veridical perceptual experiences map on to an extra-mental reality while the mental contents of dreams, illusions and hallucinations do not. But that is exactly the distinction the external world sceptic wishes to undermine. If there is no distinction, the sceptic's argument cannot get off the ground; if, however, there is a distinction, the sceptic's conclusion is false.

For Locke, even the external world sceptic must posit some sort of distinction between dreams, illusions and hallucinations and veridical perceptual experience, between, as he graphically puts it, dreaming of being in the fire and actually being in the fire (IV. ii. 14,537 and IV. xi. 8, 634-35). We naturally take the experience of the one to be caused by our interaction with an external world with which we interact and the experiences of the other to lack that etiology. That natural belief also explains the coherence of the veridical experiences and the incoherence of the non-veridical experiences. ${ }^{13}$ If this natural belief is to be challenged, the external world sceptic needs to draw a distinction between veridical and non-veridical experience and the onus is on him to provide a plausible alternative explanation of the coherence of the one and the incoherence of the other.

In the absence of some such compelling alternative explanation, it is only reasonable to adhere to our natural proclivity to firmly

13 This is emphasized at IV. xi. 7-8, 633-34, where the senses are said to 'bear witness to the Truth of each other's report, concerning the Existence of sensible Things without us'. 
believe that in veridical perception we are perceiving objects which exist external to the mind. ${ }^{14}$ As noted above, Locke believes that we have no reason to doubt of the reliability of our most basic cognitive faculties; in fact, attempts to doubt them are self-defeating and attempts to justify them are circular at best. It also needs to be reiterated that he believes that perceptual experience is one of the most basic cognitive operations; as he emphasizes, it is one of the faculties 'fitted to apprehend even what Knowledge is'.

In commenting upon the claims made in the final two sentences of the preceding paragraph the referee mentioned in footnote 9 notes that 'the claim that perceptual experience is a basic (or sufficiently basic) cognitive operation is something that someone like Descartes would reject. So even if you grant that attempts to justify reason by the use of reason are circular, it isn't immediately obvious that the same applies to perceptual experience'. While I certainly agree that Descartes would reject the claim that perceptual experience is cognitively basic and would insist that reliance on perceptual experience needs to be validated by reason, Locke, I would argue, differs from Descartes on both points. He takes perceptual experience to be cognitively basic and attempts to justify reliance upon it as misguided. To begin, as noted above, he simply refuses to take external world scepticism seriously suggesting both (a) that the external world sceptic cannot be serious, that no one can be 'uncertain of the Existence of those Things which he sees and feels' and (b) that anyone inclined to defend external world scepticism 'will never have any

14 The question of whether Locke's 'theory' of perception precludes perception of extra-mental objects is not directly germane to the focus of this paper. If it does, the tension exists between his account of perception and his claim to know of the existence of extra-mental objects, not between his talk of degrees of certainty and his claim to know of the existence of extra-mental objects. For the record, however, I do not believe that he holds a theory of perception which precludes perceiving extra-mental objects and, hence, knowing of the existence of such objects. I have argued for this in 'Is Locke An Imagist?', The Locke Newsletter 30, (1999): 17-66. 
Controversie' with him (IV. xi. 3, 631). ${ }^{15}$ The fact that he is so contemptuously dismissive of the sceptic's position, that he nowhere even attempts to justify our reliance on perceptual experience in general ${ }^{16}$, that he characterizes perceptual experience as one of the 'Faculties...fitted to apprehend even what Knowledge is' goes quite some way towards establishing that he takes perceptual experience to be cognitively basic. But the case is even stronger. Locke thinks that attempts to justify the belief that perceptual experience is experience of an external world are misguided because perceptual experience simply is the final authority on the existence and nature of an external world. This is a point emphasized in several places. IV. xi. 2, for example, states that the eyes are 'the proper and sole Judges' of whether there is a sheet of white paper in front of one; in this case the 'Testimony of the Eyes' provides a 'Certainty as great, as humane Nature is capable of, concerning the Existence of any Thing, but of Man's self alone, and of GOD' (631). IV. xi. 3 generalizes on this point, arguing that the senses provide the 'greatest assurance we are capable of concerning the Existence of material Beings'. Both

15

See also IV. xi. 8 and IV. ii. 14 for similar statements.

16

The qualification is crucial. Locke's point is that perceptual experience in general is experience of an external world, a claim that is compatible with admitting that particular 'perceptual' experiences might not be. He is quite familiar with the phenomena of hallucinations, illusions, misperceptions, etc. but does not believe that the existence of such experiences in any way undermines the reliability of perceptual experience in general. As he notes at IV. xi. 3, 631, 'If we persuade our selves, that our Faculties act and inform us right, concerning the existence of those Objects that affect them', we cannot doubt of the existence of those things we perceive. Here, when he talks of persuading ourselves that our faculties are reliable, I believe, he is emphasizing that, as long as we are confident that we are not drugged, sleep deprived, observing under non-standard perceptual conditions, etc., we may be certain of the existence of those things we perceive. He is not raising the question of how one can, in general, be confident that the senses do not deceive. As noted above, he simply dismisses that worry as not worthy of response and, furthermore, having raised the above caveat, he immediately responds with a lengthy discussion of how the senses 'bear witness to the truth of each other's report' (IV. xi. 7), a response that would be blatantly question-begging were the caveat raising a question about the general reliability of perceptual experience. It is hard to believe that a philosopher as good as Locke could be that confused. 
passages contend that the testimony of the senses provides the utmost confidence we can have concerning the existence of objects external to the mind. If the senses are the 'proper and sole' judges of the existence of material beings, if the testimony of the senses provides the 'greatest assurance' or confidence possible on these matters, if the senses provide a 'Certainty, as great as humane Nature is capable of' on these matters, no argument from reason could increase the certainty provided by the senses themselves; any attempt to validate the senses via reason would be misguided, otiose at the very least - especially since the arguments of reason could not increase the certainty provided by the senses themselves. Furthermore, any attempt to validate the senses via the senses would be circular. Quite simply, the senses are the final arbiter about the existence of an external reality and do not need to be validated by reason. Perceptual experience just is experience of an external world.

For Locke, in perceptual experience it is natural to take our experiences as experiences of extra-mental objects. He thinks that the sceptic has provided no reasonable grounds for supposing that this natural proclivity is unreliable, and reasonable doubt requires reasonable grounds. In the absence of reasonable grounds for doubt and a plausible alternative explanation of the distinction between veridical and non-veridical experiences, we are justified in firmly believing that we are perceiving external objects. In essence, Locke is shifting the burden of proof onto the sceptic; until the sceptic provides some plausible grounds for thinking that our perceptual experiences are (not just logically could be) systematically misleading, we have no grounds for thinking that they are and we are justified in thinking of perceptual experience as a source of knowledge.

As mentioned above, Locke believes that there is a second sort of epistemological incoherency in the sceptic's position. It arises this way. Perceptual experience is the final arbiter of what is real. By way of example, if in the middle of the night I wonder whether I really just heard the doorbell ring or merely dreamed that I did, I either ask my wife if she heard it or I get up and go to the door and 
look-either way, to determine whether the doorbell just rang I acquire more perceptual data. The point is: if we are unsure whether a putative perceptual experience is veridical or not, we determine the issue via further perceptual experience. While in certain circumstances it may be reasonable to doubt that some particular putative perceptual experience corresponds to reality, if our criterion for distinguishing between veridical and non-veridical perceptual experience is further perceptual experience, we cannot call into question the veridicality of all perceptual experience. As Donald Davidson points out, it is a fallacy to suppose that because some particular perceptual experiences can be non-veridical that all can be. ${ }^{17}$ Furthermore, if we seriously call into question the distinction between veridical and non-veridical perceptual experience, we no longer have any grounds for saying that some empirical claims are true and others false: we have undermined one of the faculties 'fitted to apprehend even what Knowledge is'.

Like Bacon and Hobbes, Locke simply takes it as given that a physical world exists, that we are part of that physical world and that one of the ways in which we interact with that physical world is via perceptual experience. None of the three sees any need to justify or defend these natural beliefs. As Bacon emphasizes in the Preface to the New Organon, 'The evidence of the sense, helped and aided by a certain process of correction' is retained. ${ }^{18}$ The process of correction he has in mind is rigidly controlled observations and experiments governed by stringent criteria of interpretation, i.e. disciplined observation, but observation none the less. We can rely on controlled observation and experimentation because 'the immediate perceptions of the

17 As he puts it in one place, 'Sometimes skepticism seems to rest on a simple fallacy, the fallacy of reasoning from the fact that there is nothing that we might not be wrong about to the conclusion that we might be wrong about everything'. See Donald Davidson, 'The Myth of the Subjective', in Subjective, Intersubjective, Objective (Oxford, 2001), 45.

18 Bacon, New Organon, 33-34. 
sense...do not materially mislead us'. ${ }^{19}$ Hobbes does not even deign to mention eternal world scepticism, taking it as axiomatic that our thoughts are

every one a Representation or Apparance, of some quality, or other Accident of a body without us; which is commonly called an Object...The Originall of them all, is that which we call SENSE [and the] cause of Sense, is the Externall Body, or Object, which presseth the organ proper to each Sense. ${ }^{20}$

Locke shares this natural outlook, taking it as given that perceptual experience is experience of an external world and that scepticism about the existence of an extra-mental world can be dismissed out of hand.

But, one might wonder, if he is so dismissive of external world scepticism, why does he say that sensitive knowledge is less certain than intuition or deduction. One can begin addressing that worry by noting that, for Locke, certainty is primarily a psychological or mental state. It is primarily a property of acts of affirmation, a way of holding a belief. Propositional contents are certain only in a derivative sense; they are the contents to which one firmly assents. Also, as is made clear at IV. ii. 1, degrees of knowledge or certainty are functions of 'different ways of perception' and different ways of perception have different 'degrees' of evidence. Intuition is the first 'way of perception' and produces the highest degree of certainty. In intuition 'the Mind is at no pains of proving or examining, but perceives the Truth, as the Eye doth Light, only by being directed toward it' (IV. ii. 1, 531). Intuitively perceived truths are 'irresistible', self-evident and impossible to doubt. An intuitively perceived truth 'forces it self immediately to be perceived... and leaves no room for Hesitation, Doubt, or Examination' (IV. ii. 1, 531). When one intuits that a circle is not a triangle or that three is more than two, one's assent is

19 Op. cit., Book One, aphorism XVI, 42.

20 Thomas Hobbes, Leviathan, ed. Noel Malcolm (3 vols., Oxford, 2012), ii, 22. 
so firm that not even the worries of Descartes's first meditation can make one doubt it and the person who tries to doubt it 'demands he knows not what, and shews only that he has a Mind to be a Sceptick, without being able to be so' (IV. ii. 1).

Deduction differs from intuition in several respects. First, the truths acquired via deduction are not initially irresistible, they do not force themselves upon one, i.e. they are not self-evident. In deduction the mind is 'not without pains and attention...[and] a steddy application and pursuit is required' to reach the truth (IV. ii. 4). Second, 'before the demonstration' it is possible to doubt a truth which is the conclusion of a valid deductive argument (IV. ii. 5). Such doubt may range from simply withholding one's assent to outright disbelief, as in Hobbes's initial reaction upon first encountering the Pythagorean Theorem. ${ }^{21}$ Third, and most significant, unlike truths intuitively perceived, not all truths acquired via deduction are indubitable; although a valid deduction is nothing but a chain of intuitive perceptions, there frequently is the possibility that a mistake occurred in the deduction; perhaps a mis-remembering or mis-recording occurred in the proof (IV. ii. 7). Such thoughts are reasonable when the proof is long and complicated and they easily can generate doubts about the conclusion. It is not always unreasonable to doubt the conclusion of what actually is a valid deductive argument. By the same token, despite one's conviction to the contrary, one may have made a slip in the proof and firmly assent to a proposition which is false. There are, however, steps one can take to mitigate these short comings. One can go over the proof several times oneself and ask others to check it. Since deduction is simply a chain of intuitive perceptions where each step is intuitively perceived to follow from the preceding, rechecking by oneself and others almost always eliminates any reasonable grounds of doubt. ${ }^{22}$ Nevertheless,

21 As recounted in John Aubrey, Brief Lives ed. Richard Barber (London, 1982), 152.

22 Of course this presupposes some facility with logical systems. Someone unfamiliar with formal systems might, upon first hearing of it, doubt the truth of Godel's 
because deduction is not infallible and it is possible to doubt the conclusions of particular deductive arguments, as a way of perceiving truth, it may be said to possess a lesser degree of evidence than intuition. Because there are problems for deduction that do not arise for intuition, as a means of acquiring truth deduction is said to be 'less certain' than intuition, from which it does not follow that particular beliefs acquired via deduction may not be held with certainty, i.e. held with firm assent in the absence of reasonable grounds of doubt.

The problems with perceptual experience are much more pervasive and varied than those of deduction. People misperceive, dream, hallucinate, suffer from perceptual illusions, inattentively observe, acquire beliefs under sub-optimal perceptual conditions, and go wrong in myriad ways and, just as worries about the validity or soundness of one's proof can lead one to have doubts about the conclusion, worries about the reliability of some particular perceptual experience can lead one to have doubts about the belief acquired via it. But just as there are ways of checking the conclusion of a deductive argument, there are ways of verifying a perceptually acquired belief: one can make further observations, ask others to look, etc. ${ }^{23}$ In many cases, however, the verification of a belief acquired via perception is not as conclusive as the verification of a deductive inference and doubt may linger. If my wife reports that she did not hear the doorbell ring, that does not establish that it did not - she may have been sleeping especially soundly. If I get up and look and there is no one there, that does not establish that it did not ring; perhaps neighborhood teenagers rang the bell and ran off. Alternatively, if my wife reports that she did

Theorem. If the person is not formally sophisticated and is cynical about the testimony of others, he may continue to doubt it. But it seems that in such a case there are no reasonable grounds for doubt.

23 Locke alludes to the practice of checking with others at IV. xi. 5-8. This does presuppose that other people exist, that other people are not simply items in one coherent life-long illusion or hallucination. But Locke simply refuses to play that game. While we can doubt the veridicality of particular perceptual experiences, we cannot doubt that we inhabit a physical world which we share with others and with whom we interact. 
hear it, that does not conclusively establish that it did; perhaps we both heard a sound coming from a passing car and it was only the power of my suggestion that led her to agree that it was the doorbell. Also, in many cases there simply is no possibility of verifying a particular belief acquired via perceptual experience once a plausible doubt arises: if I begin to wonder whether the bird which just flew by really was a purple finch (after all, it is late in the season for purple finches), there is now no opportunity to remove the doubt. Many perceptually-based beliefs must remain less certain than those acquired via deductive inferences. Because there are so many ways of going wrong perceptually and because techniques for removing reasonable doubt once it arises are not as successful as those for deduction, as a means of acquiring beliefs, perceptual experience is said to possess a lesser degree of evidence and certainty than either deduction or intuition. But to say that perceptual experience confronts problems not encountered by intuition or deduction and, consequently, is a 'less certain' manner of acquiring beliefs is not to say that some particular belief acquired via perceptual experience is not certain. And just as in the absence of reasonable doubt we may firmly assent to (be certain of) the conclusion of a deductive argument, in the absence of reasonable doubt we may firmly assent to a belief acquired via a perceptual experience.

For Locke, then, certainty is a property of acts of assenting; one is certain of a proposition when there are no reasonable grounds for doubt and one firmly assents to it. Furthermore, there are degrees of assent, running from assent to intuitively perceived propositions where doubt is simply impossible through assent to conclusions of deductive inferences where doubts can arise about the conclusion of a particular argument but where those doubts can usually be laid to rest through rechecking to perceptually-acquired beliefs where doubts about a particular belief can arise which cannot be assuaged. And, just as the fact that we can occasionally make a mistake in a deductive argument does not call into question the general practice of making deductive inferences, the fact that we can occasionally acquire a false belief via perceptual experience 
does not call into question the general practice of acquiring beliefs via perceptual experience. Furthermore, just as we may firmly assent to the conclusion of a deductive argument when there are no reasonable grounds for thinking that we have gone wrong, we may firmly assent to a belief acquired via perceptual experience when there are no reasonable grounds for thinking that we have misperceived, are dreaming, hallucinating, etc. In the absence of reasonable grounds for doubt, firm assent to a perceptually based belief counts as being certain of it. For Locke, then, we may be certain of the truth of particular statements about extra-mental objects and that constitutes knowledge.

By way of conclusion, for Locke, certainty is merely a matter of firm assent in the absence of reasonable grounds for doubt and since we have no reasonable grounds for doubting that perception is generally reliable, unless we have good grounds for doubting that some particular perceptual experience is non-veridical, we may be certain of the belief acquired via that perceptual experience. Once this is appreciated, the prima facie tension between equating knowledge with certainty, arguing that beliefs acquired via perceptual experience enjoy a 'lower' degree of certainty than those acquired via intuition and deduction and classifying some perceptually acquired beliefs as knowledge dissipates. There are no grounds for supposing that in classifying such beliefs as knowledge Locke is being sloppy, inconsistent or simply allowing such beliefs to 'pass under' the name of knowledge even though he knows they fall short of the criterion.

Wichita State University ${ }^{24}$

24

I am indebted to Deborah Hansen Soles for substantive comments and suggestions. 